\title{
Interhospital Transfers of Acute Care Surgery Patients: Should Care for Nontraumatic Surgical Emergencies Be Regionalized? Reply
}

\author{
Heena P. Santry • George Velmahos
}

Published online: 27 September 2012

(C) Société Internationale de Chirurgie 2012

We thank Dr. Carson for his constructive criticism. We described the limitations of this study in our discussion. Because of inadequate databases at the outlying community hospitals (OCHs), we could not compare entire cohorts and therefore were forced to use our single-institution Acute Care Surgery Database. However, our goal is to help OCHs improve their databases (which we are actively doing) and be able to analyze the data in a better way across institutions.

The fact that these patients sent from OCHs were more unwell than similar patients admitted directly to the tertiary care center (despite the fact that tertiary centers generally admit overall sicker patients) supports the claim that the transfer of many of these patients had been delayed. The severity of their illness at admission could have been avoided within a regionalized system, which provides immediate and specialized care by in-house teams around the clock.

We agree that regionalization of severe, nontraumatic surgical emergencies will require changes in the health care system. This is exactly what happened many years ago when trauma care was regionalized, and it is by universal consent that the changes were deemed beneficial to society. 